\title{
How an aggressive treatment of no-reflow phenomenon in primary percutaneous coronary intervention with high thrombus burden can achieve a grade III TIMI-flow : a case report
}

\section{Iwan Cahyo Santosa Putra ( $\nabla$ iwantjoaa@gmail.com )}

School of Medicine and Health Sciences Atma Jaya Catholic University https://orcid.org/0000-00022685-0164

Joshua Henrina

T.C. Hillers Public General Hospital

Aron Husink

EMC Hospital Tangerang

\section{Research Article}

Keywords: no-reflow phenomenon, primary PCl, nitroglycerin, heparin, GP IIb/IIla inhibitor

Posted Date: February 16th, 2022

DOI: https://doi.org/10.21203/rs.3.rs-1073799/v1

License: (c) (1) This work is licensed under a Creative Commons Attribution 4.0 International License.

Read Full License 


\section{Abstract}

Introduction: The management of the no-reflow phenomenon is still being debated by experts as there is no specific algorithm, limited recommended drug choices, and insufficient data studying the combination of drugs in currently available guidelines. Thus, in this case report, we would like to propose a new combination of drugs as an alternative to the recommended drugs of choice in the treatment of no-reflow phenomenon.

Case presentation: A patient presented to the emergency room with a complaint of chest pain 30 minutes prior to arrival. However, patient was then diagnosed with extensive anterior ST-elevation myocardial infarction Killip I caused by total occlusion of the proximal left anterior descending coronary artery. During the primary percutaneous coronary intervention, after stent deployment, angiography was performed and showed a grade I TIMI-flow without any coronary artery obstruction. We then promptly administered nitroglycerin, heparin, and eptifibatide via an intracoronary route. Post-treatment angiography results found an improvement in coronary blood flow with a grade II TIMI-flow. Intravenous administration of eptifibatide and morphine afterward successfully restored perfusion to a grade III TIMIflow.

Conclusions: Aggressive and precise treatment with a drug of choice is needed to counteract the noreflow phenomenon. Presently, only a limited range of first-line drugs can be used to treat this condition. Not only that, but several of the recommended drugs are not easily accessible, especially in developing countries. Therefore, we propose a new combination treatment consisting of nitroglycerin, heparin, and GP Ilb/Illa inhibitor as an alternative treatment of the no-reflow phenomenon.

\section{Introduction}

The no-reflow phenomenon is one of the many serious complications that can occur following percutaneous coronary intervention $(\mathrm{PCl})$ in patients with myocardial infarction [1]. This event occurs in around $12 \%-32.8 \%$ of patients that underwent primary PCI [2]. The no-reflow phenomenon can be defined as an acute reduction of coronary flow despite the absence of any epicardial occlusion during $\mathrm{PCl}$ [3]. This can lead to several fatal complications without prompt and precise treatment [4]. The management of the no-reflow phenomenon is still being debated by experts as there is no specific algorithm, limited recommended drug choices, and insufficient data regarding the combination of drugs in currently available guidelines. Furthermore, most of the recommended drugs are not widely available in several developing countries. Thus, in this case report, we would like to propose a new combination of drugs as an alternative to the recommended drugs of choice in the treatment of no-reflow phenomenon.

\section{Case Presentation}

A 41-year-old man presented to the emergency room with a complaint of chest pain 30 minutes prior to arrival. Anamnesis revealed a history of type II diabetes mellitus and without family history of 
cardiovascular disease. His vital signs were within normal limits. However, the ECG showed diffuse STelevation in leads V1-V6, I, and aVL (Fig 1).

The patient was then diagnosed with extensive anterior ST-elevation myocardial infarction (STEMI) KILLIP I. The angiogram showed a total occlusion of the proximal left anterior descending (LAD) coronary artery (Fig 2). The patient then underwent primary PCl with transradial access. Pre-dilatation was performed with a size 2.0 balloon, and coronary flow was partially restored. However, there was still a high thrombus burden at the proximal LAD coronary artery with a grade II TIMI-flow (Fig 2).

We then attempted another pre-dilatation, but the patient complained of worsening chest pain. Further examination, we found that the patient was hypotensive (BP 90/50 $\mathrm{mmHg}$ ), and the ECG showed ventricular tachycardia (HR 156 bpm) (Fig 3).

We decided to immediately implant a $3.5 \mathrm{~mm} \times 32 \mathrm{~mm}$ drug-eluting stent (DES), but this did not improve the patient's symptoms and vital signs, and the angiogram showed a grade I TIMI-flow without any coronary artery obstruction (Fig 4). Then, we administered $200 \mathrm{mcg}$ of nitroglycerin, 3000 units of unfractionated heparin, and 4,5 mg of eptifibatide through intracoronary access. We also added intravenously $10 \mathrm{mcg} / \mathrm{kg} / \mathrm{min}$ of dobutamine, $150 \mathrm{mg}$ of amiodarone, and $2 \mathrm{mcg} / \mathrm{kg} / \mathrm{min}$ of norepinephrine. Vital signs improved with BP 115/65 mmHg and HR 91 bpm, but the patient's chest pain persisted, and the angiogram showed a partially restored coronary blood flow with a grade II TIMI-flow (Fig 4). After intravenous administration of $4,5 \mathrm{mg}$ eptifibatide and $4 \mathrm{mg}$ morphine, chest pain was successfully alleviated, and the angiogram showed a totally restored coronary blood flow with a grade III TIMI-flow. (Fig 4).

We then stabilized the patient in the ICU. The echocardiographic examination three days post-primary PCI showed adequate left ventricle systolic function with an ejection fraction of $59 \%$ and was hypokinetic at the anterior cardiac wall.

\section{Conclusions}

The definitive diagnosis of a no-reflow phenomenon is established with angiography when the TIMI flow grade is 0 or 1 without any evidence of epicardial coronary obstruction [2]. There are several known risk factors of a no-reflow phenomenon, including a long target lesion $(32 \mathrm{~mm})$, a large luminal diameter $(3,5$ $\mathrm{mm})$, and a high thrombus burden, all of which were present in this case [5].

Prompt and precise management is needed in patients experiencing no-reflow as it can lead to prolonged ischemia, hemodynamic instability, left adverse ventricular remodeling, collapse, and even death [6]. It is also related to a higher prevalence of early post-infarction complications, such as arrhythmias, pericardial effusion, cardiac tamponade, and early congestive heart failure [4]. Treating the no-reflow phenomenon will not reduce the infarct size, but it can improve circulation to the necrotic area and prevent infarct expansion [3]. 
At present, guidelines are still unclear about the exact algorithm and combination of drugs that can be used to achieve reflow. Moreover, there is a limited range of recommended drug choices listed, and several of these drugs may not even be accessible in certain developing countries. Currently available guidelines on the management of no-reflow phenomenon are from The Society for Cardiovascular Angiography and Interventions (SCAI) and The European Society of Cardiology (ESC). The SCAI guidelines recommend adenosine, verapamil, or nitroprusside as the first-line drugs to treat the no-reflow phenomenon (level of evidence B) [7]. Moreover, the ESC guidelines also state that a glycoprotein (GP) $\mathrm{Ilb} / \mathrm{Illa}$ inhibitor can be used as a last resort therapy when other treatment options fail [8]

Distal embolization and microvascular vasospasm are two of the main pathomechanisms that can cause the no reflow phenomenon [9]. Accordingly, we selected specific drugs (GP Ilb/llla inhibitor, nitroglycerin, and heparin) to counteract these processes to achieve reflow. Glycoprotein llb/llla inhibitors are known for their superior ability to prevent platelet aggregation [10]. Until now, there are no clinical trials that studied the role of GP Ilb/Illa inhibitors specifically for treating the no reflow phenomenon. Still, some studies found that intracoronary GP Ilb/Illa inhibitors can improve microcirculation by reducing thrombus burden and minimizing distal embolization during $\mathrm{PCl}[11-13]$. On the other hand, nitroglycerin administration induces smooth muscle relaxation and thus vasodilatation, which helps counteract microvascular vasospasm [14]. Another case report discussing the no-reflow phenomenon found that nitroglycerin injection was able to improve coronary flow significantly [15]. Heparin also plays an important role as an anticoagulant through inhibiting thrombin and factor Xa [16]. Together with a GP $\mathrm{Ilb} / \mathrm{llla}$ inhibitor, these drugs will counteract the distal embolization process [17]. However, currently, there is a lack of case reports and clinical trials that use intracoronary heparin as a drug of choice to manage the no reflow phenomenon. For that reason, in our paper, we would like to report a successful treatment of the no-reflow phenomenon using a different combination therapy consisting of nitroglycerin, heparin, and a GP Ilb/IIla inhibitor as an alternative to the first-line drugs. Nonetheless, further clinical trials are needed to determine the effectiveness of these drug options, which are more accessible in developing countries.

Although we successfully used an alternative drug combination to achieve grade III TIMI-flow, we encountered several limitations during the process. First, as magnetic resonance imaging (MRI) was not available in our center, we could not assess the presence of any microvascular obstruction that could have occurred as a complication of no-reflow, which needs to be treated to achieve a better outcome. Additionally, there was a loss to follow up. Hence, further assessment of heart failure status, left ventricle function, and residual ischemia were not possible.

In conclusion, the no-reflow phenomenon is a serious complication that can occur during $\mathrm{PCl}$ and cause several fatal complications. Therefore, aggressive and precise treatment with a drug of choice is needed to manage this condition. Presently, only a limited range of first-line drugs can be used to treat the noreflow phenomenon. Furthermore, several of these drugs are not easily accessible, especially in developing countries. Therefore, we would like to propose a new combination treatment consisting of nitroglycerin, heparin, and GP Ilb/Illa inhibitor as an alternative treatment of the no-reflow phenomenon. 


\section{Abbreviations}

$\mathrm{PCl}$ : percutaneous coronary intervention.

STEMI : ST- elevation myocardial infarction.

TIMI :thrombolysis in myocardial infarction.

GP : glycoprotein

$L A D$ : left anterior descending.

BP : blood pressure.

bpm : beat per minute.

$\mathrm{HR}$ : heart rate.

DES : drug-eluting stent.

SCAI : The Society for Cardiovascular Angiography and Interventions.

ESC : The European Society of Cardiology.

\section{Declarations}

Ethics approval

Ethics approval was obtained from ethics committee of EMC hospital Tangerang.

\section{Consent to participate}

Written and verbal consent was obtained from the patient for this case report.

\section{Consent for publication}

Consent for publication was obtained from the patient for this case report.

\section{Availability of data and material}

Data is available upon a reasonable request. 


\section{Competing interests}

The authors declare that they have no conflicts of interest.

\section{Funding}

There is no funding in this report.

\section{Code availability}

Not applicable.

\section{Authors' contributions}

ICSP conceived and design the study. ICSP also performed literature research, acquired the data, and drafting the manuscript. JH provides revision of the manuscript. AH contributed in revision of the manuscript, supervision, and final approval of the manuscript. All authors approved the final manuscript.

\section{Acknowledgements}

There is no acknowledgements in this case report.

\section{References}

1. Klein LW, Kern MJ, Berger P, Sanborn T, Block P, Babb J, et al. Society of cardiac angiography and interventions: suggested management of the no-reflow phenomenon in the cardiac catheterization laboratory. Catheter Cardiovasc Interv Off J Soc Card Angiogr Interv. 2003 Oct;60(2):194-201.

2. Alidoosti M, Lotfi R, Lotfi-Tokaldany M, Nematipour E, Salarifar M, Poorhosseini H, et al. Correlates of the "No-Reflow" or "Slow-Flow" Phenomenon in Patients Undergoing Primary Percutaneous Coronary Intervention. J Tehran Univ Heart Cent. 2018 Jul;13(3):108-14.

3. Rezkalla Shereif H., Kloner Robert A. No-Reflow Phenomenon. Circulation. 2002 Feb 5;105(5):65662.

4. Ito H, Maruyama A, Iwakura K, Takiuchi S, Masuyama T, Hori M, et al. Clinical implications of the "no reflow" phenomenon. A predictor of complications and left ventricular remodeling in reperfused anterior wall myocardial infarction. Circulation. 1996 Jan 15;93(2):223-8.

5. Fajar JK, Heriansyah T, Rohman MS. The predictors of no reflow phenomenon after percutaneous coronary intervention in patients with ST elevation myocardial infarction: A meta-analysis. Indian Heart J. 2018 Dec;70 Suppl 3:S406-18. 
6. Niccoli G, Marino M, Spaziani C, Crea F. Prevention and treatment of no-reflow. Acute Card Care. 2010 Sep;12(3):81-91.

7. Levine GN, Bates ER, Blankenship JC, Bailey SR, Bittl JA, et al. 2011 ACCF/AHA/SCAI Guideline for Percutaneous Coronary Intervention. Circulation. 2011 Dec 6;124(23):e574-651.

8. Ibanez B, James S, Agewall S, Antunes MJ, Bucciarelli-Ducci C, Bueno H, et al. 2017 ESC Guidelines for the management of acute myocardial infarction in patients presenting with ST-segment elevationThe Task Force for the management of acute myocardial infarction in patients presenting with ST-segment elevation of the European Society of Cardiology (ESC). Eur Heart J. 2018 Jan 7;39(2):119-77.

9. Karimianpour A, Maran A. Advances in Coronary No-Reflow Phenomenon-a Contemporary Review. Curr Atheroscler Rep. 2018 Jul 5;20(9):44.

10. Lippi G, Montagnana M, Danese E, Favaloro EJ, Franchini M. Glycoprotein Ilb/Illa inhibitors: an update on the mechanism of action and use of functional testing methods to assess antiplatelet efficacy. Biomark Med. 2011 Feb;5(1):63-70.

11. Deibele AJ, Jennings LK, Tcheng JE, Neva C, Earhart AD, Gibson CM. Intracoronary Eptifibatide Bolus Administration During Percutaneous Coronary Revascularization for Acute Coronary Syndromes With Evaluation of Platelet Glycoprotein Ilb/Illa Receptor Occupancy and Platelet Function. Circulation. 2010 Feb 16;121(6):784-91.

12. Gu YL, Kampinga MA, Wieringa WG, Fokkema ML, Nijsten MW, Hillege HL, et al. Intracoronary versus intravenous administration of abciximab in patients with ST-segment elevation myocardial infarction undergoing primary percutaneous coronary intervention with thrombus aspiration: the comparison of intracoronary versus intravenous abciximab administration during emergency reperfusion of STsegment elevation myocardial infarction (CICERO) trial. Circulation. 2010 Dec 21;122(25):2709-17.

13. Thiele H, Schindler K, Friedenberger J, Eitel I, Fürnau G, Grebe E, et al. Intracoronary compared with intravenous bolus abciximab application in patients with ST-elevation myocardial infarction undergoing primary percutaneous coronary intervention: the randomized Leipzig immediate percutaneous coronary intervention abciximab IV versus IC in ST-elevation myocardial infarction trial. Circulation. 2008 Jul 1;118(1):49-57.

14. Horwitz LD. Mechanism of action and clinical use of nitroglycerin. Postgrad Med. 1973 Apr;53(4):167-9.

15. Park C-B, Cho J-M, Kim D-H, Kim C-J. Intracoronary nitroglycerin injection through a microcatheter for coronary no-reflow following percutaneous coronary intervention. Int J Cardiol. 2016 Jul 1;214:4002.

16. Jackson CM. Mechanism of heparin action. Baillieres Clin Haematol. 1990 Jul;3(3):483-504.

17. Cohen BM, Weber VJ, Blum RR, Ruck BE, Cohen DE, Haik BJ, et al. Cocktail attenuation of rotational ablation flow effects (CARAFE) study: pilot. Cathet Cardiovasc Diagn. 1996;Suppl 3:69-72.

\section{Figures}




\section{Figure 1}

The patient's 12-lead electrocardiogram before the procedure.

Legend: The 12-lead electrocardiogram showed extensive anterior STEMI.

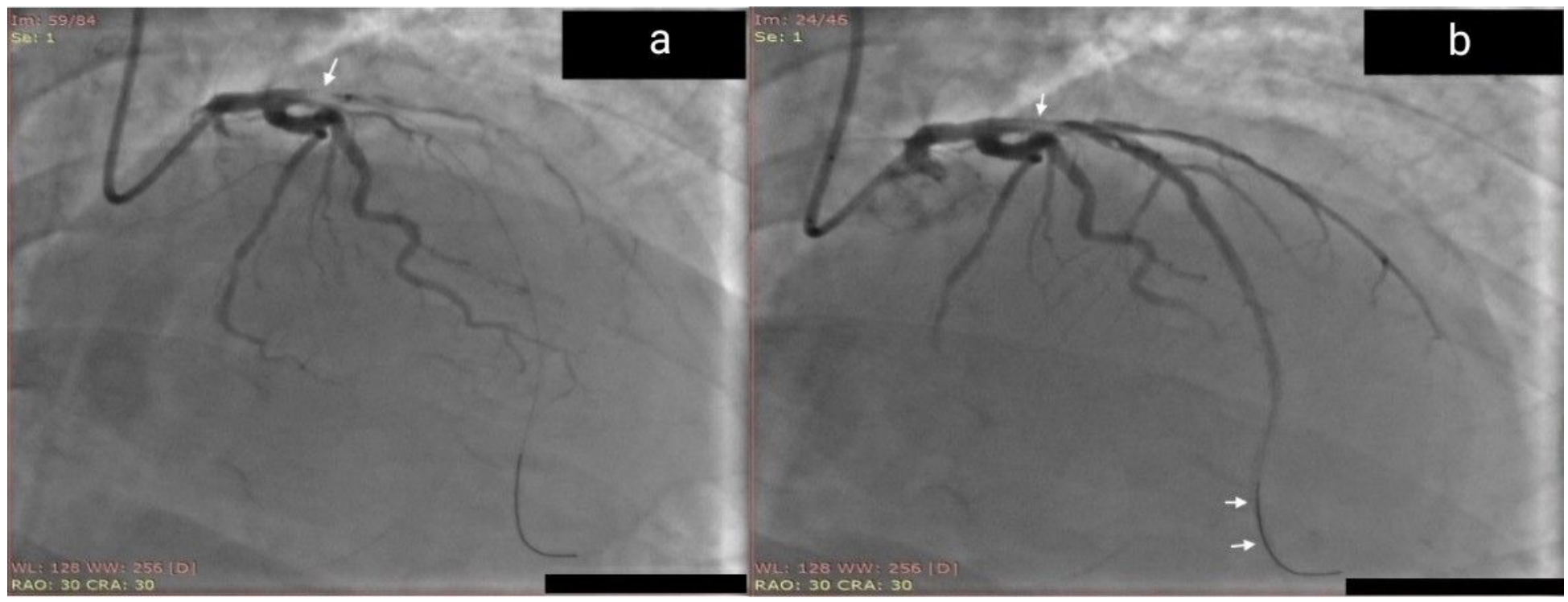

\section{Figure 2}

The patient's coronary angiography findings before monomorphic ventricular tachycardia

Legend: (a) total occlusion in proximal left anterior descending coronary artery (b) the coronary blood flow was partially restored with a grade II TIMI-flow and high thrombus burden in proximal left anterior descending coronary artery. 


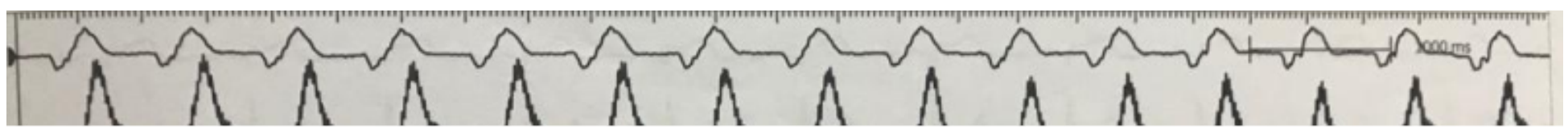

Figure 3

The patient's 12-lead electrocardiogram during the procedure.

Legend: The 12-lead electrocardiogram showed monomorphic ventricular tachycardia.

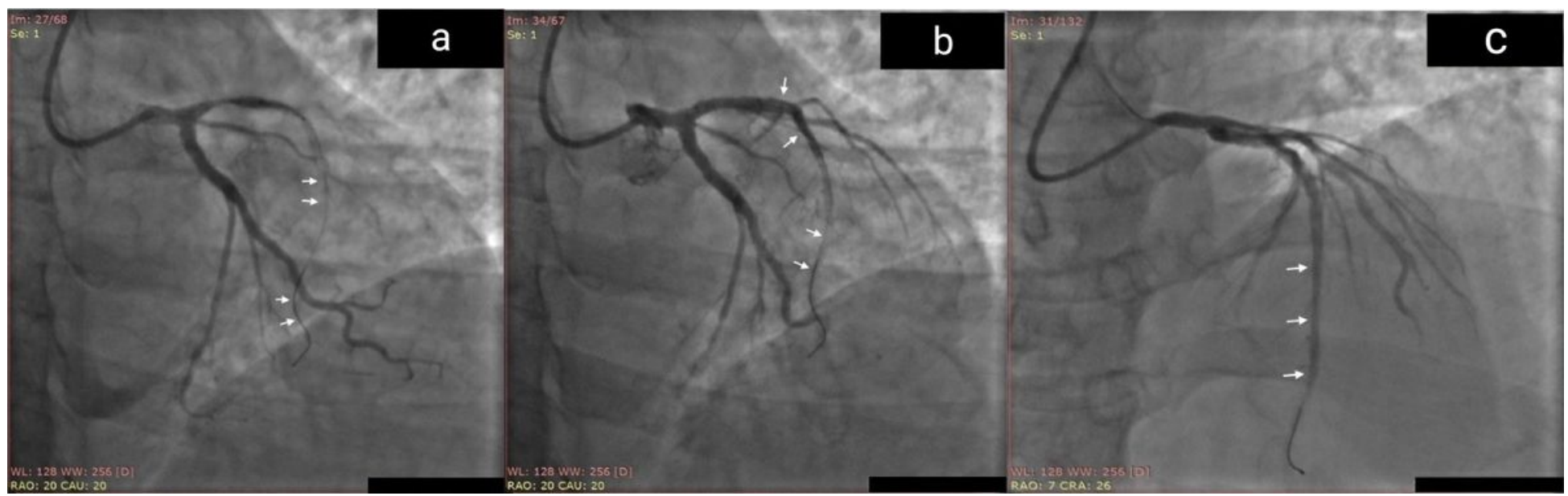

\section{Figure 4}

The patient's coronary angiography findings after monomorphic ventricular tachycardia.

Legend: (a) a grade I TIMI-flow without any coronary artery obstruction (b) the coronary blood flow was partially restored with a grade II TIMI-flow (c) the coronary blood flow was totally restored with a grade III TIMI-flow. 


\section{Supplementary Files}

This is a list of supplementary files associated with this preprint. Click to download.

- CAREchecklist2013.docx 